\section{Refractive and structural changes in infantile periocular capillary haemangioma treated with propranolol}

M Snir $1,2,3,5$, U Reich ${ }^{2,5}$, R Siegel $^{2,3}$, A Zvulunov ${ }^{4}$, R Friling ${ }^{1,3}, \mathrm{~N}$ Goldenberg-Cohen ${ }^{1,3}, \mathrm{Y}$ Ron $^{1}$ and D Ben-Amitay,

\begin{abstract}
Purpose To evaluate the optical and anatomical effects of oral propranolol treatment for infantile periocular capillary haemangioma.

Methods All children diagnosed with infantile capillary haemangioma in 2008-2010 at a tertiary paediatric medical centre underwent comprehensive evaluation, including imaging, by a multidisciplinary team followed by oral propranolol treatment. Clinical follow-up was performed regularly until the lesions disappeared. Main outcome measures included changes in anatomical extraocular extension, refractive sphere and cylindrical power, and spherical equivalent in the involved eye before and after treatment and between the two eyes.
\end{abstract}

Results A total of 30 patients (8 male; mean age at diagnosis, $1.6 \pm 2.8$ months) participated. The lesions affected the left eye in $53.3 \%$ and were located preseptally in $83.3 \%$. Four patients $(\mathbf{1 3 . 3 \%})$ received steroids before propranolol. A treatment dosage of $2 \mathrm{mg} / \mathrm{kg}$ per day was started at mean age $5.0 \pm 4.5$ months, $3.3 \pm 4.3$ months from disease onset. Side effects occurred in $\mathbf{1 1}$ patients and warranted a dose reduction (to $1 \mathrm{mg} / \mathrm{kg}$ per day) in 3 and treatment termination in 1. Findings were significant for mean reduction in involved extraocular area $(P<0.0001)$, posttreatment reduction in mean cylindrical power in involved eyes $(P=0.02)$, pre- and posttreatment differences in mean cylindrical power between involved and uninvolved eyes $(P=0.02$ and $P=0.01$, respectively), and posttreatment change in absolute values of mean spherical power between involved and uninvolved eyes $(P=0.025)$.

Conclusions Early diagnosis of infantile periocular capillary haemangioma and prompt treatment with propranolol lead to a significant reduction in the involved ocular area, in astigmatism, and prevent ocular/facial disfiguration/deformation, without rebound.

Propranolol is recommended as the preferred treatment compared with other accepted therapies.

Eye (2011) 25, 1627-1634; doi:10.1038/eye.2011.233; published online 16 September 2011

Keywords: propranolol; periocular infantile capillary haemangioma; astigmatic and spherical changes

\section{Introduction}

Infantile periocular capillary haemangioma is the most common benign vascular tumour of the eyelids/orbits in babies, with an incidence of $1.1-2.6 \%$ in full-term neonates and $4-10 \%$ in infants aged $<1$ year. ${ }^{1,2}$ It is more common in females (female/male $4.1: 2.5$ ), premature infants, and twins. The natural history of the lesion consists of a proliferative phase, lasting from 3 to 6 months up to 24 months, followed by a period of stabilization and spontaneous involution that lasts from a few months to several years. Complete regression occurs in $60 \%$ of patients by age 4 years and in $76 \%$ by age 7 years. ${ }^{3,4}$ Overall, $10 \%$ of these patients require intensive treatment during the proliferative period because of a life-threatening
${ }^{1}$ Unit of Pediatric Ophthalmology, Schneider Children's Medical Center of Israel, Petah Tiqwa, Israel

${ }^{2}$ Department of Ophthalmology, Rabin Medical Center, Petah Tiqwa, Israel

${ }^{3}$ Sackler Faculty of Medicine, Tel Aviv University, Tel Aviv, Israel

${ }^{4} U$ nit of Pediatric Dermatology, Schneider Children's Medical Center of Israel, Petah Tiqwa, Israel

Correspondence: M Snir, Unit of Pediatric Ophthalmology and Adult Strabismus, Schneider Children's Medical Center of Israel, 14 Kaplan Street, Petah Tiqwa 49202, Israel Tel: + 97239253756 or 97252 3284793;

Fax: + 97239253273 or +97237316635.

E-mail: msnir@clalit.org.il or moshesnir@hotmail.com ${ }^{5}$ These authors contributed equally to this work.

Received: 3 June 2011 Accepted in revised form: 26 July 2011

Published online: 16 September 2011 
location, local anatomical and functional complications, or facial-disfiguring risks. ${ }^{5-7}$

The exact aetiology of capillary haemangiomas is unclear, with involvement of angiogenic and vasculogenic factors. ${ }^{8}$ In the angiogenesis pathway, new blood vessels arise from remodelling of pre-existing vasculature. Accordingly, capillary haemangiomas are composed of endothelial cells, mast cells, macrophages, and cellular factors such as the angiogenesis-related receptor E-selectin intergrins, $\alpha \mathrm{V} \beta 3$ and $\alpha 5 \beta 1$, and basic fibroblast growth factor (bFGF). ${ }^{9,10}$ The proliferative phase is characterised by elevated levels of vascular endothelial growth factor and insulin-like growth factor 2, which promote lesion growth from existing vessels. ${ }^{11,12}$ The vasculogenesis pathway is implicated by findings that the early endothelial structures and the cellular part of these structures originate from mesoderm-derived haemangioblasts that function as progenitors for haematopoietic and endothelial cells. The proliferation and involution phases are controlled by various regulators and include molecular, cellular, and hormonal changes. ${ }^{11,12}$

Focal infantile periocular capillary haemangioma is associated with a $46-80 \%$ rate of severe complications. ${ }^{13}$ It can cause ptosis, displacement of the globe, and mechanical deformation of the immature sclera and cornea, leading to anisometropic astigmatism and refractive amblyopia. ${ }^{13-15}$ In severe cases, it can cause disfiguring proptosis, exposure keratitis, compressive optic neuropathy, and facial/lid deformation. ${ }^{16,17}$

First-line therapy with corticosteroids: systemic (oral and intravenous), through local intralesional injection, periorbital infusion, or combined intralesional and posterior sub-Tenon's infusion yielded anatomical and refractive improvement. ${ }^{18-20}$ However, prolonged treatment with several sessions sometimes required general anaesthesia for proper administration, and posed a risk of serious ocular and systemic side effects. ${ }^{21}$ In cases of steroid-resistant lesions, second-line therapy with interferon- $a$ and vincristine had an almost $100 \%$ success rate, but adverse reactions ranged from minor to very severe. ${ }^{8,22}$ In 2008, Léauté-Labrèze et $a l^{23}$ reported that propranolol administered for decreased cardiac output in a child with a capillary haemangioma led to permanent regression of the lesion. This finding was confirmed in another report of 11 children treated with propranolol for capillary haemangioma. ${ }^{24,25}$

The aim of this study was to determine the efficacy and advantages/disadvantages of propranolol treatment for infantile periocular capillary haemangioma and to evaluate propranolol-induced anatomical and functional changes in the lesion.

\section{Patients and methods}

\section{Setting}

A retrospective, comparative, interventional study design was used. The study group comprised children diagnosed with an extensive capillary haemangioma in the proliferative phase from June 2008 to June 2010 and treated with propranolol. The study was conducted at the Schneider Children's Medical Center of Israel, a university-affiliated tertiary hospital. The protocol was approved by the Institutional Review Board of the Rabin Medical Center, Beilinson Hospital, and approval was confirmed by the directorship of the Schneider Children's Medical Center of Israel.

\section{Pretreatment procedure}

All patients underwent pretreatment evaluation by a multidisciplinary team consisting of a paediatrician, paediatric ophthalmologist, orthoptist, paediatric dermatologist, and radiologist. The ophthalmic examination included the size and extent of the lesion (periorbital and orbital), facial/ocular disfiguration, intraocular pressure measured using a Tono-Pen XL (Medtronic Solar, Jacksonville, FL, USA), funduscopy performed using an indirect ophthalmoscope, and cycloplegic refraction examination with two successive administrations of cyclophenolate $0.5 \%$ with phenylephrine $2.5 \%, 10 \mathrm{~min}$ apart. The orthoptic evaluation included ocular motility, duction, version, and vergence, as well as the alternate prism cover test or Hirschberg's test. The dermatological evaluation covered the extent, size, colour, and rigidity of the lesion. Most of the children also underwent magnetic resonance imaging with contrast material to determine the full periocular extension of the lesion.

The criteria for propranolol treatment were a mutually confirmed diagnosis of infantile periocular capillary haemangioma by a paediatric ophthalmologist and dermatologist and findings of partial/total occlusion of the visual axis, pressure, or displacement of the eye globe, or significant refractive anisometropia, proptosis, and disfiguring malformation of the eyelids and face. Patients with other ocular or neurological problems or craniosynostosis were excluded, as were patients with other periorbital and orbital vascular or lymphatic lesions, known allergy to propranolol, and asthma or other upper respiratory tract disease.

Candidates for systemic oral propranolol therapy were referred for thorough cardiac evaluation, including electrocardiography and echocardiography, to rule out contraindications. In addition, digital colour photographs were taken of the periorbital involvement; findings were analysed using the NIH Image J software, 
version 14.3U (NIH, Bethesda, MD, USA), a public domain program, downloaded from the NIH website (http://rsbweb.nih.gov/ij). ${ }^{26}$ The involved area was determined by circling the lesion area in free hand and then measuring all diseased areas in centimetres squared. Owing to lapses in patient cooperation, the photographs were not always taken from the same distance, and the lesion sometimes appeared larger or smaller in successive images. Therefore, to standardise measurements, we used the corneal horizontal diameter, white to white, as a constant 11.5-mm scale for each photograph (Figure 1).

\section{Treatment}

Before onset of propranolol treatment, parents / guardians were given a detailed explanation of the disease, the treatment plan, and potential side effects of the drug, and all signed an informed consent form to participate in the study.

Propranolol, $2 \mathrm{mg} / \mathrm{kg}$ per day in two doses, was initiated with supervision either in the Day Care Unit or during $24 \mathrm{~h}$ hospitalisation in one of the paediatric departments. Blood pressure, pulse rate, and blood glucose levels were monitored during hospitalisation and again during clinic follow-up after 1 week and then every 6-8 weeks for the duration of the systemic therapy. After cessation of therapy, ocular follow-up continued for several months depending on the clinical abnormality. In addition, at each routine medical visit, the dermatological evaluation was repeated, together with ophthalmic/orthoptic evaluations of vascular lesion size, ocular anterior and posterior segments, visual axis, ptosis, ocular motility, misalignment, and cycloplegic refraction. Patients with significant refractive anisometropia (mainly astigmatism) or partial occlusion of the visual axis were prescribed glasses; those older than 4 months were also given antiamblyopia treatment. The preoperative cardiac evaluation and periorbital digital imaging were repeated at the last follow-up visit. Treatment tolerance was determined according to the findings of the ophthalmologist and the dermatologist and parental reports of side effects. Systemic adverse effects were measured by the paediatrician, including blood pressure, glucose level, and pulse rate. In cases of severe early and late systemic side effects or life-threatening effects of propranolol, the ophthalmologist and dermatologist weighed the need to lower the dosage or discontinue therapy.
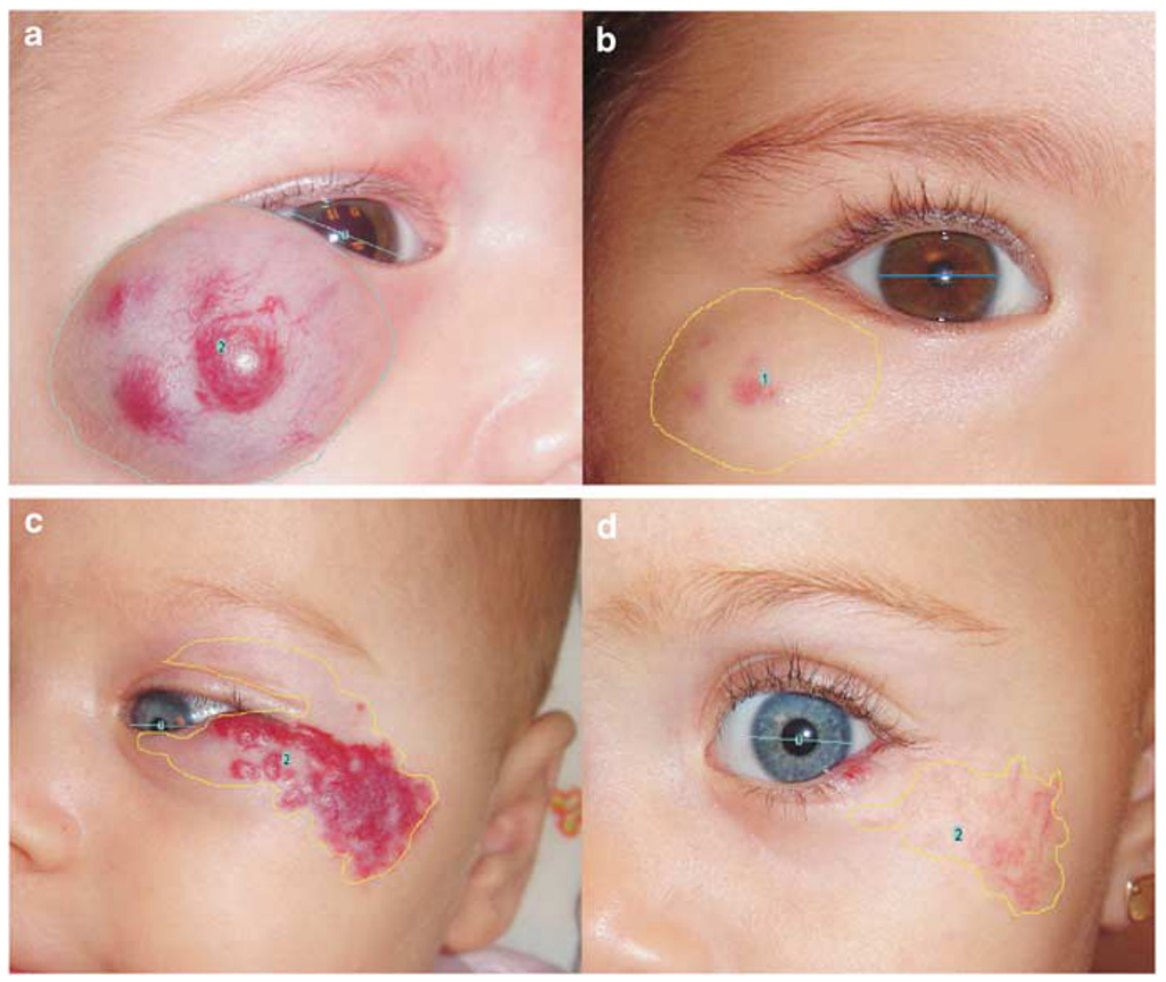

Figure 1 Infantile periocular capillary haemangioma before and after propranolol therapy. (a, b) Patient 1: A 4-month-old child with demarcated severe right perioculary capillary haemangioma, before and after a 6-month course of propranolol. The significant lesion shrinkage as measured by the corneal diameter scale (white to white) must be noted. (c, d) Patient 2: A 5-month-old child with demarcated severe left periocular capillary haemangioma, before and after a 6-month course of propranolol. The significant lesion shrinkage as measured by the corneal diameter scale (white to white) must be noted. 


\section{Data collection}

Patient files were reviewed for the following data: age at initiation and termination of treatment, interval from appearance of the lesion to start of therapy, duration of therapy, dosage, total/partial treatment, changes in the three refractive parameters in the involved and healthy eyes and from before to after treatment, side effects of treatment, need for suppurative ocular treatment after systemic therapy, and absolute changes in the involved area after treatment.

A successful treatment result was defined as significant reductions in lesion size $(>50 \%)$, lesion extension $(>50 \%)$, disfigurement, and the three refractive parameters (namely spherical power, cylinder power, and spherical equivalent) in the involved eye $v s$ the healthy eye.

\section{Statistical analysis}

The Wilcoxon-matched pairs signed-rank test was used to analyse anatomical (lesion-related) and functional (refraction) changes from baseline to after treatment within each involved eye and between the involved and healthy eyes. We also analysed the absolute changes in sphere and cylindrical power and spherical equivalent. A $P$-value of 0.05 was considered significant. All analyses were performed using the Statistical Package for the Social Sciences (IBM SPSS 17.0.0; Professional Statistics release 6.29/2010, SPSS Inc., Somers, NY, USA).

\section{Results}

In all, 30 infants ( 8 male and 22 female) met the study criteria. Their characteristics are shown in Table 1 . The mean age at diagnosis was $1.6 \pm 2.8$ months (range 0.25-15 months). The lesion affected the left eye in $53.3 \%$ of patients and was located preseptally in $83.3 \%$. Four patients $(13.3 \%)$ were treated briefly with steroids before propranolol. The mean age at treatment initiation was $5.0 \pm 4.5$ months (range 1.0-7.0 months), and the mean interval from diagnosis to start of therapy was $3.3 \pm 4.3$ months (range $0.25-16.5$ months). The mean duration of treatment was $7.3 \pm 3.5$ months (range 1.5-15.0 months), and the duration range of follow-up after cessation of therapy was 6-10 months.

A total of 26 babies (86.7\%) underwent maximal treatment of $2 \mathrm{mg} / \mathrm{kg}$ per day. In all, 11 patients (36.6\%) had side effects of treatment according to their medical files. In three of them (10.0\%), the dose was partially decreased (to $1 \mathrm{mg} / \mathrm{kg}$ per day) because of severe wheezing, difficulty breathing, and loss of appetite; two of the three patients also had diarrhoea and vomiting. No change in dosage was made in the remainder, in whom
Table 1 Clinical data of 30 infants with PICH

\begin{tabular}{|c|c|}
\hline Characteristics & Number (\%) \\
\hline \multicolumn{2}{|l|}{ Sex, n $(\%)$} \\
\hline Male & $8(26.7)$ \\
\hline Female & $22(73.3)$ \\
\hline \multicolumn{2}{|l|}{ Laterality, n (\%) } \\
\hline Right & $12(40)$ \\
\hline Left & $16(53.3)$ \\
\hline Bilateral & $2(6.7)$ \\
\hline \multicolumn{2}{|l|}{ Location, n (\%) } \\
\hline Preseptal & $25(83.3)$ \\
\hline Preseptal + intraorbital (extraconal) & $3(10)$ \\
\hline Preseptal + intraorbital (extraconal + intraconal) & $1(3.3)$ \\
\hline Preseptal + intraconal and intracranial & $1(3.3)$ \\
\hline \multicolumn{2}{|l|}{ Mean age at diagnosis (months) } \\
\hline Mean \pm SD & $1.6 \pm 2.8$ \\
\hline Range & $0.2-15.0$ \\
\hline \multicolumn{2}{|l|}{ Age at treatment initiation (months) } \\
\hline Mean $\pm S D$ & $5.0 \pm 4.5$ \\
\hline Range & $1.0-17.0$ \\
\hline \multicolumn{2}{|l|}{ Interval from diagnosis to treatment (months) } \\
\hline Mean \pm SD & $3.3 \pm 4.3$ \\
\hline Range & $0.5-16.5$ \\
\hline \multicolumn{2}{|l|}{ Duration of treatment (months) } \\
\hline Mean $\pm S D$ & $7.3 \pm 3.5$ \\
\hline Range & $1.0-15.0$ \\
\hline Follow-up after cessation of therapy (months) & $6-10$ \\
\hline \multicolumn{2}{|l|}{ Lesion size $\left(\mathrm{cm}^{2}\right)$} \\
\hline Mean \pm SD & $12.7 \pm 21.7$ \\
\hline Range & $1.21-108.15$ \\
\hline
\end{tabular}

adverse effects included transient episodes of sleep problems (three patients), restlessness (three patients), or fever (two patients). Treatment was stopped in one patient $(3.3 \%)$ because of a respiratory tract infection. There were no abnormal findings on intensive monitoring of blood pressure, pulse rate, and blood glucose level.

Anatomical improvement was noted within 2-4 days of initiation of treatment in all patients: the lesion became paler and softer, and there was some shrinkage in lesion size, thickness, and extension. These parameters continued to improve longitudinally until the end of treatment. The periorbital photographs of 24 patients (80\%) were appropriate for the digital calculation program. The findings revealed a mean diseased periorbital area of $12.7 \pm 21.7 \mathrm{~cm}^{2}$ before therapy and $6.0 \pm 9.5 \mathrm{~cm}^{2}$ after therapy, for a reduction of $>50 \%$ $(P<0.0003)$ (Table 2$)$. Treatment was stopped when the 
Table 2 Refraction and anatomical results of oral propranolol treatment for infantile periocular capillary haemangioma

\begin{tabular}{lcccc}
\hline Parameter & Before treatment & After treatment & Improvement & P-value* \\
\hline Spherical power $(D)$ & $1.9 \pm 1.6$ & $1.3 \pm 0.6$ & $31 \%$ & 0.13 \\
Cylindrical power $(D)$ & $1.0 \pm 1.1$ & $0.6 \pm 0.7$ & $41 \%$ & 0.02 \\
Spherical equivalent $(D)$ & $1.8 \pm 1.6$ & $1.3 \pm 0.8$ & $28 \%$ & 0.1 \\
Involved area $\left(\mathrm{cm}^{2}\right)$ & $12.7 \pm 21.7$ & $6.0 \pm 9.5$ & $52.5 \%$ & $<0.0003$ \\
\hline
\end{tabular}

*Wilcoxon-matched pairs signed-rank test; $P \leq 0.05$ was considered significant.

Table 3 Differences in refractive parameters between the involved and healthy eyes before and after treatment

\begin{tabular}{|c|c|c|c|c|c|c|c|c|}
\hline \multirow[t]{2}{*}{ Parameter } & \multicolumn{4}{|c|}{ Before treatment } & \multicolumn{4}{|c|}{ After treatment } \\
\hline & Involved eye & Healthy eye & Difference (\%) & P-value & Involved eye & Healthy eye & Difference (\%) & P-value* \\
\hline Mean spherical power $(D)$ & $1.9 \pm 1.6$ & $1.3 \pm 2.0$ & 30.0 & 0.9 & $1.3 \pm 0.6$ & $1.2 \pm 1.0$ & 9.1 & 0.13 \\
\hline Mean cylinder power $(D)$ & $1.0 \pm 1.1$ & $0.5 \pm 0.6$ & 50.0 & 0.02 & $0.6 \pm 0.7$ & $0.3 \pm 0.5$ & 47.0 & 0.01 \\
\hline Mean spherical equivalent & $1.8 \pm 1.5$ & $1.8 \pm 1.5$ & 1.5 & 1.0 & $1.3 \pm 0.8$ & $1.3 \pm 0.7$ & 0.8 & 0.8 \\
\hline
\end{tabular}

*Wilcoxon-matched pairs signed-rank test; $P \leq 0.05$ was considered significant.

lesion shrank to the point that it was nearly flat and had almost disappeared, with only mild residual skin colour changes and residual superficial telangiectasia, and no lid/facial disfiguration.

A total of 21 patients (70\%) underwent cycloplegic refraction examinations. The refractive changes are shown in Tables 2 and 3. Analysis revealed a significant reduction of $40.5 \%$ in mean cylindrical power in the involved eye after treatment compared with baseline $(P=0.02)$. There was a non-significant reduction of $31 \%$ in spherical power $(P=0.13)$, and a non-significant decrease of $28 \%$ in mean spherical equivalent $(P=0.1)$ (Table 2). A significant difference was noted in mean cylindrical power between the involved and uninvolved eyes both before and after treatment $(P=0.02$ and $P=0.01$, respectively) (Table 3 ). The difference in absolute values of the refractive error changes before $v s$ after treatment in the involved eye (mean $-0.6 \pm 1.4$ ) and healthy eye (mean $-0.2 \pm 1.7$ ) revealed a significant difference in the mean sphere $(D)(P=0.025)$. No significant refractive change was found in the healthy eye at any point.

Three patients $(10 \%)$ were prescribed anti-amblyopia treatment consisting of a patch over the healthy eye with or without glasses.

There were no events of hypotension, bradycardia, or hypoglycaemia during treatment. There was no deterioration in anatomical or refractive parameters after cessation of treatment, during the post-treatment follow-up period.

\section{Discussion}

This study indicates that propranolol is the recommended treatment for babies with a massive periocular capillary haemangioma in the proliferative phase. The administration of propranolol at a steady dose of $2 \mathrm{mg} / \mathrm{kg}$ per day significantly reduced the anatomical and functional pathology, thereby preventing refractive amblyopia and ocular/facial disfiguration or deformation within a short time, without rebound. Side effects were relatively few and treatable.

Researchers are seeking appropriate replacements for steroids as the first-line therapy for infantile periocular capillary haemangioma, especially in patients with combined refractory periorbital and orbital disease.

Propranolol is a non-selective $\beta$-blocker. It has been found to have a beneficial effect on infantile periocular capillary haemangioma, but the underlying mechanism is unknown. ${ }^{26,27}$ Three possibilities have been proposed: (1) a vasoconstrictive effect caused by $\beta$-2-adrenergic receptor binding in capillary endothelial cells; (2) decreased expression of genes controlling such angiogenic factors as VEGF and bFGF that modify signal transduction in the RAF-mitogen-activated protein kinase pathway; and (3) hypoxia-induced capillaryendothelial cell apoptosis. Propranolol may affect capillary haemangiomas at the proliferative or involution stages. Studies have reported a propranolol-reduced structural regression in capillary haemangiomas, together with dramatic functional refractive improvement, within 1-4 days of drug initiation. ${ }^{27-32}$ Léauté-Labrèze et $a l^{24}$ were the first to describe rapid anatomical shrinkage already $24 \mathrm{~h}$ after treatment initiation in 11 babies. After the lesion flattened, patients were able to satisfactorily open their eyes; there was no visual impairment. Taban and Goldberg ${ }^{32}$ administered propranolol to a 6-year-old girl with a capillary haemangioma who had failed to respond to steroids. Improvement was noted after a few days. The lesion 
ultimately disappeared completely, with no regrowth. Similarly, in a study of 17 infants with propranololtreated capillary haemangioma, Al Dhaybi et al ${ }^{33}$ observed a reduction in lesion size within 2 months in all cases. In our study, patients showed marked improvement within 2-4 days of treatment initiation. The colour of the lesion faded, and it became softer and smaller. Missoi et $a l^{34}$ and Haider et $a l^{35}$ reported on 17 children who were treated orally from age 4.5 months and age 3 weeks to 12 months, respectively. Anatomical improvement was observed within a few days. Cheng et $a l^{36}$ (5 patients) and Fridman et $a l^{37}$ (10 patients) observed anatomical improvement in most cases within 1 day and 1 week, respectively.

The mean duration of treatment in our study was $7.3 \pm 3.5$ months, which is longer than that reported by others: 6.5 months in the 11 patients treated by LéautéLabréze et $a l^{24}$ and 5.5 months in the 17 patients treated by Al Dhaybi et $a l^{33}$ This difference may be related to the considerably greater number of participants in our study and our more frequent monitoring and calculations of the anatomical changes. We also used a specific digital imaging software to delineate the new lesion limits after regression and calculated the involved area at each measurement. ${ }^{25}$ In this manner, we were able to objectively and directly pace the healing process. To the best of our knowledge, this technique has not been used in other studies as part of the regular clinical follow-up of patients with propranolol-treated capillary

haemangioma. By the end of treatment, the mean diseased area had decreased significantly $(P<0.0003)$, with minor residual skin pigmentary changes and superficial telangiectasis.

Meticulous analysis of the refractive parameters yielded several significant changes from before to after treatment in the involved eye and between the two eyes. The change in the spherical component after treatment in the involved eye (31\%) was not statistically significant after treatment $(P=0.15)$, but the difference in the absolute value of the spherical component (from one time point to the next) between the involved and uninvolved eyes was significant $(P=0.025)$. For the cylindrical component, the percentage change with treatment $(41 \%)$ was significant $(P=0.02)$, as were the differences between the two eyes both before treatment $(P=0.02)$ and after $(P=0.01)$. These changes in spherical and cylindrical powers in the involved eye were directly related to the shrinkage of the haemangioma, which allowed for normal globe development. Fabian et $a l^{38}$ in a study of three patients with a massive periocular capillary haemangioma, demonstrated the efficacy of propranolol in decreasing astigmatic error and preventing amblyopia in the involved eye. Cheng et al ${ }^{36}$ and Haider et $a l^{35}$ reported a reduction in anisometropic astigmatism after treatment in a few patients, but the difference was not statistically significant.

Our repeated cycloplegic refraction measurements helped us to analyze the status of refractive error and treatment-induced changes. We found that when the astigmatic error was high and the refractive differences between the two eyes were significant $(n=3,12.5 \%)$, supplemental anti-amblyopia treatment, in the form of patching of the healthy eye with or without glasses, was successful. In addition, careful monitoring clearly revealed the point at which the cycloplegic refraction stabilized, providing an objective indicator of when to terminate systemic $\beta$-blocker therapy. It is noteworthy that the refractive status of the fellow eye did not change significantly.

We observed mostly minor side effects of sleep disturbances, agitation, and fever that were successfully managed by the paediatrician with no change in the treatment protocol. None of our patients had bradycardia, hypotension, or hypoglycaemia. We attribute this last finding to the meticulous pretreatment evaluation, followed by close monitoring during and after treatment. We had to reduce the dosage in three cases $(50 \%)$ to $1 \mathrm{mg} / \mathrm{kg}$ per day because of breathing difficulties, vomiting, loss of appetite, and diarrhoea, and to discontinue treatment in one patient because of a severe respiratory tract infection. Sans et $a l^{39}$ also reported minor side effects of propranolol, such as hypotension and wheezing, in 2 of 32 patients with infantile periocular capillary haemangioma, and $\mathrm{Al}$ Dhaybi et $a l^{33}$ reported diarrhoea or sleep disturbances in 5 of 17 patients. Missoi et $a l^{34}$ observed mild side effects in most patients, but treatment had to be discontinued in only one patient because of brief episodes of bradycardia. Haider et $a l^{35}$ noted mild side effects (gastric problems and fatigue) in 6 of 17 patients (35.3\%), which did not warrant a switch or termination of the medication.

It is noteworthy that the application of topical $\beta$-blocker solution (timolol maleate $0.5 \%$ ) for superficial periocular capillary haemangioma led to significant improvement (visual axis clearance) within a few weeks. ${ }^{40,41}$ The response times were longer, and no local or systemic adverse effects were noted.

Our study is unique in several specific parameters: (1) the large sample size, (2) long duration of treatment and follow-up (3) post-treatment ocular follow-up, (4) meticulous analysis of the refractive changes in the involved eye compared with the uninvolved eye, and (5) digital analysis of the involved area before and after treatment.

In conclusion, early and prompt administration of oral propranolol to a dose of $2 \mathrm{mg} / \mathrm{kg}$ per day is recommended for massive and deep proliferative-stage infantile periocular capillary haemangioma. The use of 
propranolol in this setting requires multidisciplinary supervision by a paediatrician, paediatric ophthalmologist, orthoptist, and paediatric dermatologist. In our series, the improvements were dramatic, both structurally and functionally. Structurally, the vascular lesion disappeared without ocular/facial deformation. Functionally, spherical and astigmatic errors of refraction decreased significantly, which prevented amblyopia in the involved eye. These changes were maximal and permanent, without rebound. Side effects were mostly minor.

\section{Summary}

\section{What was known before}

- Infantile periocular capillary haemangioma is the most common benign vascular tumour of the eyelids/orbits in babies, which requires intensive treatment for local anatomical, functional, and cosmetic risks.

- Treatment with corticosteroids, interferon- $\alpha$, and vincristine is unsatisfactory.

- Propranolol is the newest treatment modality.

What this study adds

- Our study is unique for the large cohort size, long duration of treatment and follow-up, post-treatment ocular follow-up, analysis of the refractive changes in the involved and uninvolved eyes, and digital analysis of the involved area before and after treatment.

\section{Conflict of interest}

The authors declare no conflict of interest.

\section{Acknowledgements}

No grants or sponsorships have been requisitioned for this study. The authors do not have any commercial interest in any product or procedure mentioned in this manuscript.

\section{References}

1 Kilcline C, Frieden IJ. Infantile hemangiomas: how common are they? A systematic review of the medical literature. Pediatr Dermatol 2008; 25: 168-173.

2 Eivazi B, Ardelean M, Bäumler W, Berlien HP, Cremer H, Elluru $\mathrm{R}$ et al. Update on hemangiomas and vascular malformations of the head and neck. Eur Arch Otorhinolaryngol 2009; 266(2): 187-197.

3 Ceisler E, Blei F. Ophthalmic issues in hemangiomas of infancy. Lymphat Res Biol 2003; 1: 321-330.

4 Frieden IJ, Haggstrom AN, Drolet BA, Mancini AJ, Friedlander SF, Boon L et al. Infantile hemangiomas: current knowledge, future directions. Proceedings of a Research Workshop on Infantile Hemangiomas, April 7-9, 2005,
Bethesda, Maryland, USA. Pediatr Dermatol 2005; 22: 383-406.

5 Wasserman BN, Medow NB, Homa-Palladino M, Hoehn ME. Treatment of periocular capillary hemangiomas. J AAPOS 2004; 8: 175-181.

6 Bauland CG, van Steensel MA, Steijlen PM, Rieu PN, Spauwen PH. The pathogenesis of hemangiomas: a review. Plast Reconstr Surg 2006; 117: 29e-35e.

7 Stigmar G, Crawford JS, Ward CM, Thomson HG. Ophthalmic sequelae of infantile hemangiomas of the eyelids and orbit. Am J Ophthalmol 1978; 85: 806-813.

8 Ritter MR, Butschek RA, Friedlander M, Friedlander SF. Pathogenesis of infantile haemangioma: new molecular and cellular insights. Expert Rev Mol Med 2007; 9: 1-19.

9 Chang EI, Chang EI, Thangarajah H, Hamou C, Gurtner GC. Hypoxia, hormones, and endothelial progenitor cells in hemangioma. Lymphat Res Biol 2007; 5: 237-243.

10 Barnés CM, Christison-Lagay EA, Folkman J. The placenta theory and the origin of infantile hemangioma. Lymphat Res Biol 2007; 5: 245-255.

11 Sommers Smith SK, Smith DM. Beta blockade induces apoptosis in cultured capillary endothelial cells. In Vitro Cell Dev Biol Anim 2002; 38: 298-304.

12 Razon MJ, Kraling BM, Mulliken JB, Bischoff J. Increased apoptosis coincides with onset of involution in infantile hemangioma. Microcirculation 1998; 5: 189-195.

13 Robb RM. Refractive errors associated with hemangiomas of the eyelids and orbit in infancy. Am J Ophthalmol 1977; 83: $52-58$.

14 Schwartz SR, Blei F, Ceisler E, Steele M, Furlan L, Kodsi S. Risk factors for amblyopia in children with capillary hemangiomas of the eyelids and orbit. J AAPOS 2006; 10: 262-268.

15 Weiss AH, Kelly JP. Reappraisal of astigmatism induced by periocular capillary haemangioma and treatment with intralesional corticosteroid injection. Ophthalmology 2008; 115: 390-397.

16 Mitchell DE, Freeman RD, Millodot M, Haegerstrom G. Meridional amblyopia: evidence for modification of the human visual system by early visual experience. Vision Res 1973; 13: 535-558.

17 Levi M, Schwartz S, Blei F, Ceisler E, Steele M, Furlan L et al. Surgical treatment of capillary hemangiomas causing amblyopia. J AAPOS 2007; 11: 230-234.

18 Nguyen J, Fay A. Pharmacologic therapy for periocular infantile hemangiomas: a review of the literature. Semin Ophthalmol 2009; 24: 178-184.

19 Pope E, Krafchik BR, Macarthur C, Stempak D, Stephens D, Weinstein $\mathrm{M}$ et al. Oral vs high-dose pulse corticosteroids for problematic infantile hemangiomas: a randomized, controlled trial. Pediatrics 2007; 119: e1239-e1247.

20 Friling R, Axer-Siegel R, Ben-Amitai D, Goldenberg-Cohen $\mathrm{N}$, Weinberger $\mathrm{D}$, Snir M. Intralesional and sub-Tenon's infusion of corticosteroids for treatment of refractory periorbital and orbital capillary haemangioma. Eye (Lond) 2009; 23: 1302-1307.

21 Shorr N, Seiff SR. Central retinal artery occlusion associated with periocular corticosteroid injection for juvenile hemangioma. Ophthalmic Surg 1986; 17: 229-231.

22 Greinwald Jr JH, Burke DK, Bonthius DJ, Bauman NM, Smith RJ. An update on the treatment of hemangiomas in children with interferon alfa-2a. Arch Otolaryngol Head Neck Surg 1999; 125: 21-27. 
23 Léauté-Labrèze C, Taïeb A. Efficacy of beta-blockers in infantile capillary haemangiomas: the physiopathological significance and therapeutic consequences (article in French). Ann Dermatol Venereol 2008; 135: 860-862.

24 Léauté-Labrèze $C$, Dumas de la Roque E, Hubiche T, Boralevi F, Thambo JB, Taïeb A. Propranolol for severe hemangiomas of infancy. N Engl J Med 2008; 358: 2649-2651.

25 Image J. Image Processing and Analysis in JAVA. Available at:http://rsbweb.nih.gov/ij. Accessed 29 June 2010.

26 Bigorre M, Van Kien AK, Valette H. Beta-blocking agent for treatment of infantile hemangioma. Plast Reconstr Surg 2009; 123: 195e-196e.

27 Siegfried EC, Keenan WJ, Al-Jureidini S. More on propranolol for hemangiomas of infancy. Comment on: $N$ Engl J Med 2008; 358: 2649-2651.

28 Sans V, de la Roque ED, Berge J, Grenier N, Boralevi F, Mazereeuw-Hautier J et al. Propranolol for severe infantile hemangiomas: follow-up report. Pediatrics 2009; 124: e423-e431.

29 Propranolol in capillary hemangiomas. Available at http://clinicaltrials.gov/ct2/show/NCT00744185. Accessed 20 October 2009.

30 Propranolol versus prednisolone for treatment of symptomatic hemangiomas. Available at http://clinicaltrials.gov/ct2/show/NCT00967226. Accessed 20 October 2009.

31 Fay A, Nguyen J, Jakobiec FA, Meyer-Junghaenel L, Waner M. Propranolol for isolated orbital infantile hemangioma. Arch Ophthalmol 2010; 128: 256-258.

32 Taban M, Goldberg RA. Propranolol for orbital hemangioma. Ophthalmology 2010; 117: 195-195.e4.
33 Al Dhaybi R, Millet A, McCuaig C. Treatment of periocular infantile hemangiomas with propranolol: a review of 17 cases. Pediatr Dermatol 2009; 26: 666.

34 Missoi TG, Lueder GT, Gilbertson K, Bayliss SJ. Oral propranolol for treatment of periocular infantile hemangiomas. Arch Ophthalmol 2011; 29: 899-903.

35 Haider KM, Plager DA, Neely DE, Eikenberry J, Haggstrom A. Outpatient treatment of periocular infantile hemangiomas with oral propranolol. J AAPOS 2010; 14: 251-256.

36 Cheng JF, Gole GA, Sullivan TJ. Propranolol in the management of periorbital infantile hemangioma. Clin Exp Ophthalmol 2010; 38: 547-553. doi: 10.1111/j.14429071.2010.02344.x.

37 Fridman G, Grieser E, Hill R, Khuddus N, Bersani T, Slonim C. Propranolol for the treatment of orbital infantile hemangiomas. Ophthal Plast Reconstr Surg 2011; 27: 190-194.

38 Fabian ID, Ben-Zion I, Samuel C, Spierer A. Reduction in astigmatism using propranolol as first-line therapy for periocular capillary hemangioma. Am J Ophthalmol 2011; 151: 53-58.

39 Sans V, Dumas de la Roque E, Berge J, Grenier N, Boralevi F, Mazereeuw-Hautier J et al. Propranolol for severe infantile hemangiomas: follow-up report. Pediatrics 2009; 124: e423-e440.

40 Guo S, Ni N. Topical treatment for capillary hemangioma of the eyelid using beta-blocker solution. Arch Ophthalmol 2010; 128: 255-256.

41 Ni N, Langer P, Wagner R, Guo S. Topical timolol for periocular hemangioma: report of further study. Arch Ophthalmol 2011; 129: 377-379. 